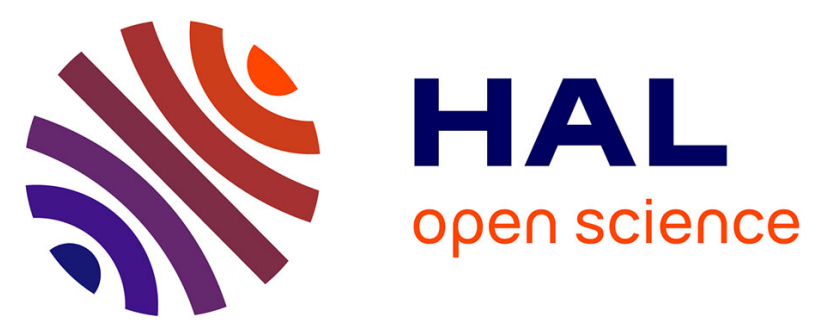

\title{
PARAMETRIC COST ANALYSIS FOR WEB BASED E-COMMERCE OF LAYER MANUFACTURED OBJECTS
}

Paolo Di Stefano, Luca Di Angelo

\section{- To cite this version:}

Paolo Di Stefano, Luca Di Angelo. PARAMETRIC COST ANALYSIS FOR WEB BASED ECOMMERCE OF LAYER MANUFACTURED OBJECTS. International Journal of Production Research, 2010, 48 (07), pp.2127-2140. 10.1080/00207540802183653 . hal-00565117

\section{HAL Id: hal-00565117 https://hal.science/hal-00565117}

Submitted on 11 Feb 2011

HAL is a multi-disciplinary open access archive for the deposit and dissemination of scientific research documents, whether they are published or not. The documents may come from teaching and research institutions in France or abroad, or from public or private research centers.
L'archive ouverte pluridisciplinaire HAL, est destinée au dépôt et à la diffusion de documents scientifiques de niveau recherche, publiés ou non, émanant des établissements d'enseignement et de recherche français ou étrangers, des laboratoires publics ou privés. 


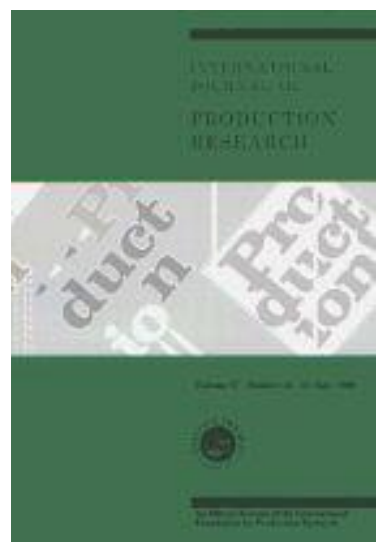

PARAMETRIC COST ANALYSIS FOR WEB BASED E-COMMERCE OF LAYER MANUFACTURED OBJECTS

\begin{tabular}{|r|l|}
\hline Journal: & International Journal of Production Research \\
\hline Manuscript ID: & TPRS-2008-IJPR-0118 \\
\hline Manuscript Type: & Original Manuscript \\
\hline Author: & $10-$ Seb-2008 \\
\hline Complete List of Authors: & $\begin{array}{l}\text { Di Stefano, Paolo; Universita\&apos; degli Studi di L\&apos;Aquila, } \\
\text { Department of Mechanical Engineering } \\
\text { Di Angelo, Luca; Università degli Studi di L'Aquila, Department of } \\
\text { Mechanical Engineering }\end{array}$ \\
\hline Keywords: & RAPID PROTOTYPING, COST ESTIMATING, E-COMMERCE \\
\hline Keywords (user): & RAPID PROTOTYPING, COST ESTIMATING \\
\hline &
\end{tabular}

\section{(5)holarONE" \\ Manuscript Central}




\title{
PARAMETRIC COST ANALYSIS FOR WEB BASED E-COMMERCE OF LAYER MANUFACTURED OBJECTS
}

\author{
DI ANGELO, Luca $^{(1)}$; DI STEFANO, Paolo ${ }^{(2)}$ \\ University of L'Aquila, Italy \\ Department of Mechanical Engineering, Energy and Management \\ email: diangelo@ing.univaq.it ${ }^{(2)}$ dspla@ing.univaq.it
}

\begin{abstract}
WEB based e-commerce of rapid prototyping services is going to be a widely diffused methodology used to compete in a global market. A competitive market imposes a very accurate estimation of prototyping price. Prototype costs depend on many factors, some of which may be easily deduced, while some others consist in a complex function of the geometric model properties and of the specific technology employed to build a physical model. Build time, which affects some components of the prototype's build cost, is a critical factor to deduce. Build time depends not only on the prototype dimensions but also on the complexity of the shape that, in turn, affects the movement of the tool to form the object.

A parametric approach to build cost estimation, suited for WEB based e-commerce, is presented in this paper. Significant cost driving factors of layer manufactured objects are identified and instruments to evaluate them are proposed. Special attention has been paid to define a parametric approach to build time estimation. The proposed parametric approach analyzes the geometrical features, which typically affect the build time of the main layer manufacturing technologies. The method is verified in some test cases related to FDM technology.
\end{abstract}

Keywords: rapid prototyping, cost estimating, e-commerce.

\section{Introduction}

As a result of the diffusion of internet, e-business systems are the latest progress on information technology and business process improvement. In fact, many web-based applications have been developed to reduce transaction cycle time (Huang et al., 2003; Luol et al., 2004) in rapid prototyping 
services. The high level of competition characterizing the rapid prototyping service market requires competitive prices, fast quotation times and high quality products. One of the objectives of a company selling on-line is to increase its share of the market until it reaches production saturation capacity. The market reference for a company, which sells on-line, may reach international levels without a major increase in costs. Rapid prototyping service is an activity that works well on the web. The product specification may be formulated using a geometric model defined by a file that can easily surf the net even at great distances. The distribution network of shipping is characterized by an international dimension, capillary coverage of territory, fast delivery and relatively low costs. The combination of these elements has led the major companies, which operate in the Rapid Prototyping (R.P.) sector, to get equipped with suitable instruments for quoting and selling their services on-line.

Both the products sold and the distinctiveness of the customers requiring these services make this form of on-line selling different from other previous types of thriving e-commerce. It is important to bear in mind that the purchaser requiring these services is usually developing a new product for his company and discretion regarding such a product is essential and in some cases even strategic; therefore, the company supplying the service must guarantee the utmost confidentiality. For a company operating in the rapid prototyping sector, the necessity to expand its market share has an essential prerequisite: the possibility to supply quotations while at the same time satisfying the privacy that the customer demands. The discretion required in outsourcing rapid prototyping means that on-line quotations need to be made without transferring the geometric model. It is possible to solve this problem by dedicated software, available to purchasers, which is capable of remotely analyzing the geometric model, without the need to transfer any files. From the geometric model the software deduces parameters influencing the manufacturing cost (cost driving factors), and transmits the data to the manufacturer in order to make a quotation for the prototype. The quotation process can also be performed automatically. This approach guarantees the confidentiality of the purchaser's product, while at the same time providing the manufacturing company with an instrument that automatically formulates a quotation, which is constantly updated on actual costs. This could lead to particularly competitive quotations which are also dictated by the need to saturate a machine load [A. S. Gogate and S. S. Pande 2007].

One of the current tendencies is for companies in the rapid prototyping sector to be equipped with numerous prototype technologies in order to satisfy the wide range of customers' needs. The various layer manufacturing technologies differ not only in the material used but also in the operating principle and the modalities with which the material is deposited on each single prototype slice. The cost of an object made with rapid prototyping depends on numerous factors, some of which are easy to determine, 
while some others are more closely linked to the type of technology used. One of the most important factors influencing costs is the time involved in manufacturing the object, which is very difficult to estimate. Build time depends not only on the object dimension but also on the object complexity and on the R.P. technology used, which affect necessary movements of the forming tool. For this reason build time could not be easily evaluated from a remote station by using general purpose software. In order to estimate build time it is common practice to assume that it is proportional to the total volume of the prototype. In practice this approach only provides one component of the total build time. In a particularly competitive market, the error margin in production cost forecasting, and consequently, in price, is greatly reduced; therefore, such approximation cannot be accepted. The real risk is the estimation of either a non-profitable price or an excessive price which could drive the purchaser away. In order to perform a remote estimation of the build cost, a new parametric approach is proposed, which also takes into account build-time prevision. It is based on the evaluation of some driving factors, which give the possibility to estimate cost without transferring the geometric model. This approach can be adapted for the cost estimation of the most common layer manufactured technologies. A procedure is defined to evaluate the coefficients of the parametric formula for build time estimation. The complete method is verified in some test cases that have been used in other research works described in literature.

\section{Layer manufacturing technology costs' structure}

Rapid prototyping costs comprise different components. Alexander et al. (1998) identify three main cost components: prebuild cost $\left(C_{\text {pre }}\right)$, build cost $\left(C_{\text {build }}\right)$ and postprocessing cost $\left(C_{\text {post }}\right)$.

Prebuild cost refers to any preparation jobs performed before the part is manufactured and in turn, comprises:

- Verification of the integrity of the geometric model and eventual repair (if the geometric model is not free from faults it must be rejected by the remote software);

- Definition of the layers' thickness $(L)$ and build direction (d) (Build direction is defined by the purchaser that knows the geometric model; this is one limit of the e-commerce of R.P.).

In e-commerce of R.P., prebuild cost cannot be estimated and it must be taken as a fixed value assigned to each unit produced.

Postprocessing costs comprise the works necessary to: remove supports; finish the surface model to obtain the desired surface quality, including extra operations such as polishing; smooth down surface 
roughness; paint, etc. Postprocessing costs' evaluation is performed (or made) by multiplying the time required for the related activities by their unitary cost. This time can be assumed as a function of geometric model parameters such as the size of the external surface area $(\mathrm{S})$.

Build costs' components can be assigned to the prototype either as a function of addition of object and support volume $\left(V_{\text {mod }}+V_{\text {sup }}\right)$, or as a function of the build time. The cost components which are functions of the object volume are:

- Material's and support material's costs which also include expenses caused by scrap and spoilage;

- auxiliary materials.

The cost components which are function of the build time are:

- the labor component;

- machine depreciation;

- power consumption;

- nonproduction labor and maintenance.

The driving factor of the above cost components is the ratio between the build time required to produce it $\left(t_{f}\right)$ and the total productive time $(T)$.

Prebuild, build and postprocessing costs can be directly assigned to a specific prototype and they are all grouped under the direct costs category. Indirect costs, on the contrary, include administration, secretarial work, cleaning, utilities, indirect materials and other costs that arise independently from production levels and cannot be assigned directly to the products. Indirect costs for a single prototype can be allocated in different ways, which are specific to each company. Very often, indirect costs are evaluated as the product of the ratio $t_{f} / T$ and a cost factor ( $U_{\text {comp }}$ ) that characterizes company management.

The total cost of the prototype is the sum of four main components:

$$
C_{T O T}=C_{\text {pre }}+C_{\text {build }}+C_{\text {post }}+C_{\text {indirect }}
$$

Some variable costs components are function of the prototype orientation (d); some others are function of manufacturing time, while others only depend on geometric parameters (volume, external surface area).

$$
C_{T O T}=C_{\text {pre }}+\left[C_{\text {mat }}+C_{\text {sup }}(\mathbf{d})+C_{\text {cons }}\left(t_{f}\right)+C_{\text {fixed }}\left(t_{f} / T\right)\right]+\left[C_{\text {sup }}^{\prime}(\mathbf{d})+C_{\text {fin }}\right]+C_{\text {indirect }}\left(t_{f} / T\right)
$$

where:

$$
\mathrm{C}_{\text {pre }}=\text { prebuild cost; }
$$


$\mathrm{C}_{\text {mat }}=$ material's cost;

$\mathrm{C}_{\text {sup }}(\mathbf{d})=$ support material's cost;

$\mathrm{C}_{\text {cons }}\left(t_{f}\right)=$ power consumption and auxiliary materials;

$\mathrm{C}_{\text {fixed }}\left(t_{f} / T\right)=$ other fixed costs;

$\mathrm{C}^{\prime}{ }_{\text {sup }}(\mathbf{d})=$ cost of removing support material;

$\mathrm{C}_{\text {fin }}=$ surface finishing cost;

$\mathrm{C}_{\text {indirect }}\left(t_{f} / T\right)=$ indirect cost.

Build cost estimation requires that both the prototype orientation and build time are known. Whereas prototype orientation is an assigned factor, build time must be estimated, so that the accuracy of cost evaluation depends on the accuracy of build time estimation. For this reason, many studies (Cheng et al., 1995; Frank and Fadel, 1995; Alexander et al., 1998; Majhi et al., 1998; Byun and Lee Kwan H., 2006) have been carried out regarding build time estimation problems.

The costs of material and surface finish are independent from prototyping direction and build time. These cost components can be estimated as a linear combination of geometric parameters that are characteristic of the object. Material cost $\left(\mathrm{C}_{\mathrm{mat}}\right)$ is a linear function of the prototype volume $\left(\mathrm{V}_{\mathrm{mod}}\right)$, which is multiplied by the unitary cost of the material $\left(\mathrm{U}_{\text {mat }}\right)$ :

$$
C_{m a t}=V_{m o d} * U_{m a t}
$$

The cost to finish the surface of the prototype $\left(C_{f i n}\right)$ can be calculated as the product of the size of surface area $\left(S_{\text {mod }}\right)$ and the unitary cost of working $\left(U_{\text {fin }}\right)$ :

$$
C_{f i n}=S_{m o d} * U_{f i n}
$$

\subsection{Cost components dependent on prototype orientation}

In rapid prototyping technologies, the prototype orientation can be selected without any manufacturing constraint. Nevertheless, it is important to bear in mind that prototype orientation affects some important factors, such as surface finish, build time, support structure, shrinkage and curling, some of which concern prototype quality. Prototype orientation can be chosen to minimize build costs and maximize surface quality. The surface quality of a rapid prototype depends on the staircase effect on inclined and curved surfaces. Surfaces, whose triangular facets are parallel or orthogonal to the build direction, have the best finishing. Moreover, the orientation of a prototype affects the space occupied in the prototyping machine. Occupation must be estimated to evaluate the height, which fixes the number of slices, and the space in the horizontal plane which, in turn, affects the number and dimensions of 
others prototypes that can be built in the meantime. Practically speaking, the occupation of space in a prototyping machine is estimated as the dimensions of the bounding box of the geometric model $\left(b_{x}(\boldsymbol{d})\right.$, $\left.b_{y}(\boldsymbol{d}), b_{z}(\boldsymbol{d})\right)$, which is the minimal rectangular-base straight prism that contains the object. Besides, the amount of supports material, necessary to manufacture a rapid prototype, depends on the object orientation. Indicating the supports material volume with $V_{\text {sup }}(\boldsymbol{d})$ and relative unit cost with $U_{m s}$, the cost of the supports material is:

$$
C_{\text {sup }}=V_{\text {sup }}(\boldsymbol{d}) * U_{m s}
$$

Except for selective laser sintering, which does not require supports, support material cost affects all typical layer manufacturing technologies. The material of the supports is specific for each technology: e.g., whereas in stereolithography it is the same used to construct the model, in FDM the supports are done with a different material, which is soluble in water.

Once the prototype has been built, the supports must be removed. The cost for removing supports depends on the size of the surface area of the object $\left(S_{\text {sup }}(\mathbf{d})\right)$ required for the supports:

$$
C_{\text {sup }}^{,}=S_{\text {sup }}(\mathbf{d}) * U_{r s}
$$

where Urs is the unitary cost of working to remove supports from the model.

Although build direction largely affects costs, it is important to notice that in e-commerce of R.P., the build direction is typically chosen by the purchaser, who knows the object geometry and the surface quality targets.

\subsection{Cost components dependent on build-time}

Build time $t_{f}$ depends on the characteristics of the layer manufacturing process, as well as on the geometry, the dimensions and the orientation of the prototype (Kechagias et al., 2004). It is difficult to accurately calculate build time without taking into account all process parameters which affect machine movements, including acceleration and deceleration of the manufacturing tool (nozzle or laser beam) (Alexander et al., 1998). Build time can be determined as the sum of the time required to form each layer. Layer forming time depends on the tool movements required to form the layer contours and the tool path loops necessary to form the internal part of the layer. The time required to execute a single tool path depends both on the tool path length and on the repositioning number of the forming tool (figure 1). The time which is necessary to form a single layer also comprises: the time for cooling or for solidification of deposited material; the non-productive time for prototype vertical movement and other 
auxiliary unproductive activities such as nozzle cleaning.

\section{Figure 1: Layer filling path}

There exists no general function to estimate build time but specific formulas can be defined, each of them adapted for a specific machine that uses a specific technology. Some methods for build time estimation are presented in literature (Jiangand P. Fukuda S 2001, Alexander et al., 1998; Giannatsis et al., 2001; Luo et al., 2003; Byun and Lee, 2006; Zhao et al., 2006). These methods calculate the total build time by computing the geometry through a detailed analysis of the activities associated to the prototyping process. These methods can only be used if combined with the slicing software and the tool path generator, which are dedicated to a specific layer manufacturing technology. The difficulty of generalization from specific technologies makes this approach unsuitable for e-commerce, where the geometric model analysis is carried out remotely by general purpose software. In order to evaluate build time for e-commerce, it is more useful to use a parametric-based approach which estimates build time as a function of some parameters deduced from geometric model.

\section{The proposed method for build time estimation}

STL is the standard universally accepted to describe the geometric model in commercial systems for rapid prototyping. This standard defines the boundary of the geometric model by means of a discrete set of adjacent, planar triangular facets. The parametric model used to estimate build time requires that some significant parameters should be identified from the geometric model. These parameters are defined by taking into account the STL standard. Parameters must be independent from each other so that any build time components can be evaluated separately. E-commerce applications impose that these parameters should also be independent from the specific technology used to produce the prototype. The same method can be used to estimate costs for all the rapid prototyping technologies available in a company by modifying the values of the coefficients to be multiplied by the relative parameters. Cheng et al., 1995 and Frank and Fadel, 1995, aiming to search for the minimal cost build direction, propose a simple parametric approach which assumes build time to be proportional to the slices' number $\left(b_{z} / L\right)$. Xu et al., 1999, proposed a more sophisticated parametric approach which considers build time as the sum of layers' deposition time and total delay time between subsequent layers' deposition: 


$$
t_{f}=\left(V_{\text {mat }} / L\right) \cdot t_{s}+\left(b_{z} / L\right) \cdot t_{w}
$$

where:

$b_{z}=$ prototype height;

$L=$ layer thickness;

$t_{s}=$ solidifying rate or material's deposition rate in the build time;

$t_{w}=$ delay time between subsequent layers' deposition;

$V_{\text {mat }}=$ volume of material to be formed.

Formula (8) is easy to implement but it does not take into account the complexity of the geometric model associated to the presence of holes and to the complexity of layers' contours; these factors affect unproductive times for movements and the repositioning of the manufacturing tool. For this reason, in this work formula (8) has been improved by adding two new components of build time, both defined in parametric form. The build time components considered are associated to the layers' contours' depositions and to the repositioning of the tool. In any typical commercial rapid prototyping technology the deposition time of layers' contours is proportional to the sum of contour length for each layer. For a geometric model described by triangular facets, the total length of layers' contour is:

$$
p=\frac{\sum_{j=1}^{n_{T}} \sqrt{\left(1-\left(d \bullet \mathbf{n}_{j}\right)^{2}\right)} \cdot S_{j}}{L}
$$

where:

$$
\begin{aligned}
& \boldsymbol{n}_{j}=\text { unit normal vector at triangular facet } j \text {-th; } \\
& n_{T}=\text { number of the triangular facets. } \\
& S_{j}=\text { area of } j \text {-th triangular facet; } \\
& \mathbf{d}=\text { building model direction. }
\end{aligned}
$$

The term $\sqrt{\left(1-\left(d \bullet \mathbf{n}_{j}\right)^{2}\right)} \cdot S_{j}$ is the maximal value of the area of the $j$-th triangle projected in a vertical plane (figure 2). Formula (9) can be easily implemented; $p$ parameter is calculated once the geometric model is given, and both build direction (d) and layer thickness $(L)$ assigned.

Time for tool repositioning is a function of the number of repositioning necessary to hatch the internal part of layers. The number of tool repositioning depends on prototype orientation and on the hatching vector $(\tau)$ in the $\mathbf{x}-\mathbf{y}$ plane (figure 3). In order to estimate the number of tool repositioning, the following formula is introduced: 


$$
n_{\text {repos }}=\frac{1}{H \cdot L} \sum_{j=1}^{n_{T}} \sqrt{\left(1-\left(d \bullet \mathbf{n}_{j}\right)^{2}\right)} \cdot S_{j} \cdot\left(\left|\boldsymbol{\tau} \bullet \mathbf{n}_{j, x y}\right|\right)
$$

where:

$$
\begin{aligned}
& H=\text { hatch distance between two subsequent segments of tool path (figure } 3 \text { ); } \\
& \mathbf{n}_{j}=\text { unit normal vector at } j^{\text {th }} \text { triangular facet; } \\
& \mathbf{n}_{j, x y}=\text { unit normal vector at } j^{\text {th }} \text { triangular facet projected on stratification plane; } \\
& S_{j}=\text { area of } j^{\text {th }} \text { triangular facet; } \\
& \boldsymbol{\tau}=\text { hatching vector; }
\end{aligned}
$$

Figure 2: Vertical projection of the $j^{\text {th }}$ triangle
Figure 3: Hatch distance and tool repositioning number

Many commercial R.P. technologies layer material by alternating hatching vectors which are, in consecutive stratification layers, orthogonal. In these cases, the tool repositioning number can be evaluated as the average value of $n_{\text {repos }}$ calculated for two orthogonal hatching directions:

$$
n_{\text {repos }}=\frac{1}{2 \cdot H \cdot L} \sum_{j=1}^{n_{T}} \sqrt{\left(1-\left(d \bullet \mathbf{n}_{j}\right)^{2}\right)} \cdot S_{j} \cdot\left(\left|\boldsymbol{\tau}_{0} \bullet \mathbf{n}_{j, x y}\right|+\left|\boldsymbol{\tau}_{90} \bullet \mathbf{n}_{j, x y}\right|\right)
$$

Both formulas (10) and (11) can be calculated once the geometric model and the technological parameters $(L, \boldsymbol{\tau}$ and $H)$ are known.

Under the hypothesis that new build time components are linear functions of the total contour length and of the number of tool repositionings, the build time is:

$$
t_{f}=\left(\frac{V}{L}-p \cdot W\right) \cdot t_{s}+\left(\frac{b_{z}}{L}\right) \cdot t_{w}+\alpha \cdot n_{\text {repos }}+\beta \cdot p
$$

where:

$t_{s}=$ solidifying rate or material deposition rate in the build time;

$t_{w}=$ delay time between each layer's deposition of material;

$\alpha=$ proportionality coefficient for material tip repositionings number;

$\beta=$ proportionality coefficient for material layers' perimeter;

$W=$ material line segments width (figure 1).

The first term of formula (8) has been redefined in (12) by taking into account the time required to 
build layers' contours.

The approach used to estimate build time for material stratification can also be used to calculate supports' build time. Some prototypes could require supports that are non-connected regions; in these cases, a more appropriate value for the total height of supports, $b_{z \text {,sup }}$ must be deduced according to the rule in figure 4.

\section{Figure 4: Rule for the evaluation of supports' total height $\left(b_{z, \text { sup }}\right)$.}

The total build time can be estimated as follows:

$$
\begin{aligned}
& t_{f}=\left(\frac{V_{\text {mat }}}{L}-p_{\text {mat }} \cdot W_{\text {mat }}\right) \cdot t_{s, \text { mat }}+\left(\frac{b_{z, \text { mat }}}{L}\right) \cdot t_{w, \text { mat }}+\alpha_{\text {mat }} \cdot n_{\text {repos } \text { mat }}+\beta_{\text {mat }} \cdot p_{\text {mat }}+ \\
& \left(\frac{V_{\text {sup }}}{L}-p_{\text {sup }} \cdot W_{\text {sup }}\right) \cdot t_{s, \text { sup }}+\left(\frac{b_{z \text { sup }}}{L}\right) \cdot t_{w, \text { sup }}+\alpha_{\text {sup }} \cdot n_{\text {repos }}+\beta_{\text {sup }} \cdot p_{\text {sup }}
\end{aligned}
$$

where the subscript mat refers to prototype and subscript sup refers to supports.

\section{Experimental tests}

The proposed method has been verified in a set of specifically-designed experiments. For these experiments, an R.P. machine with FDM technology (Fused Deposition Modelling) has been employed; the related technical specifications are quoted in table 1. Real build times have been measured for each model analysed. Geometric parameters are computed by processing the geometric model with the original software developed by the authors which implements the proposed model.

Table 1: Principal technical specifications of the used layer manufacturing machine.

The first set of experiments has been conducted to examine the dependence of build time on tool repositioning number. For this purpose, the geometric models considered are characterized by equal values for the total layer contour length, volume and height. A set of geometric models satisfying the previously mentioned conditions has been defined by using a prismatic object which has been rotated, as regards the building direction, in some assigned positions (Figure 5a). As a consequence of the prismatic model rotation, a different tool repositioning number is required. In figure $5 \mathrm{~b}$ the build time for each of the 15 prismatic objects, defined as formerly, is quoted as a function of the tool 
repositioning number evaluated by using formula (11). The results of the experimental tests validate the assumed hypothesis that build time is a linear function of the tool repositioning number: the coefficient of determination of the linear fitting regression is $R^{2}=0.9933$ and the straight line slope is $\beta_{\text {mat }}=$ 0.00318 .

\section{Figure 5: Build time as a function of estimated repositioning number}

In a second set of experiments, in order to investigate the dependence of build time on the total length of layers' contour, the volume and height have been fixed. For this purpose, 6 rectangular-based prismatic objects, with different ratios for the base sides, have been taken into consideration. Build times are quoted in figure 6 (trend $\mathrm{A}$ ) as a function of the total contour length, which has been calculated using formula (9).

The tool repositioning number and the total length of the contour affect two independent build time components, although they are correlated. For an assigned hatching vector the tool repositioning number increases as the total length of the contour increases. Build time (figure 6 trend A) is affected by two components: the number of tool repositionings and the total length of layer contours. In order to identify the contribution of $p$ to build time, the component that deals with tool repositioning has been subtracted from the measured build time. In figure 6 (trend B) the build time component which is relevant to contour forming is quoted as a function of the total contour length $p$. The hypothesis that build time is a linear function of the total contour length (calculated as in formula (9)) is substantially verified: the coefficient of determination of the fitted regression is $\mathrm{R}^{2}=0.9946$ and the straight line slope is $\alpha_{m a t}=0.0009$. The approach followed to estimate build time coefficients $\alpha_{m a t}$ and $\beta_{\text {mat }}$ has been used to evaluate the analogous coefficients for the support build time formula $\left(\alpha_{\text {sup }}\right.$ and $\left.\beta_{\text {sup }}\right)$.

In order to estimate the remaining coefficients in formula (13) $\left(t_{s, \text { mat }}, t_{w, \text { mat }}, t_{s, \text { sup }}\right.$, and $\left.t_{w, \text { sup }}\right)$ another set of experiments have been conducted. Twenty different geometric models have been taken into consideration and, for each of them, the parameters in equation (13) have been evaluated $\left(V_{\text {mat }}, b_{z, \text { mat }}\right.$, $\left.n_{\text {repos mat }}, p_{\text {mat }}, V_{\text {sup }}, b_{z \text {,sup }}, n_{\text {repos sup }}, p_{\text {sup }}\right)$. The unknown coefficients have been obtained by solving the overdetermined system defined by the equation (13) applied to the 20 experiments, by means of the square root method. The obtained values of the eight coefficients are quoted in table 2.

\section{Figure 6: Influence of the total contour length on build time of prismatic prototypes}


Table 2: Values of the eight coefficients of the mathematical model for build time estimation.

In order to validate the build-time model proposed, this has been applied to calculate the build time of six test cases taken from literature (figure 7) (Huang et al., 2003; Kechagias et al., 2004; Byun and Lee, 2006). These cases present some critical features that contribute to the difficulty of predicting build time (small thickness and holes). The estimated build times are compared to the actual process: results and errors are quoted in table 3. Although literature data refer to manufacturing processes which are different from FDM, the comparison of performances is however possible because the time driving factors are substantially the same and they are common to the most diffused R.P. technologies.

\section{Table 3: Results obtained for the six test cases selected}

The average of the absolute value of error, in the test cases (table 3), is $5.65 \%$, and the maximum error is $15.13 \%$. The results obtained show the good performance of the proposed method especially when compared to the results presented in literature (Huang et al., 2003; Kechagias et al., 2004; Byun and Lee, 2006). Furthermore, it is important to notice that build time estimations reported in literature should be more accurate intrinsically because they are dedicated to specific R.P. technologies and are designed to perform a detailed analysis of the movements of the forming tool.

Figure 7: Test cases used to validate the proposed method

\section{Conclusions}

An accurate prediction of build time is essential in order to calculate the precise cost of a layer manufacturing object. The methods for build time prediction can be dedicated to specific technologies or based on a parametric approach. The first approach requires that a lot of information, dealing with the kinematics and dynamical performances of the machine, should be known; for this reason, this approach cannot be used to remotely compute the geometric model, that is to say, following a technology independent approach. Parametric models are of general purpose and relatively simple to implement. Thus, they are suitable for e-commerce of R.P. The parametric methods described in literature only provide a component of the total build time: they do not take into account the complexity of the geometric model, which affects unproductive times for movements and the repositioning of deposition apparatus of all R.P. technologies. 
In this paper, a new parametric model is proposed, which satisfies the requirement of simplicity (necessary for implementation in the WEB for e-commerce) and provides a quite accurate estimation of build time (even in critical cases and when supports are required). Despite the fact that some improvement have been introduced, the new parametric model cannot perform the detailed analysis of activities required to manufacture an object. For this reason, some build time components, such as the time necessary to repose the forming tool after each tool path, are neglected. Other build time components cannot be strictly evaluated but must be assumed as medium values: for example, the speed of the deposition tool is, implicitly, assumed as constant. The proposed method requires that some process parameters should be known $(L, H, \mathrm{~W}$ and $\boldsymbol{\tau})$. Therefore, the procedure for e-commerce requires that necessary manufacturing parameters should be sent to the remote software.

The new method has been applied to estimate the build time of some test cases which are characterised by some critical features that contribute to the difficulty in build time prediction (small thickness and holes). The results obtained show good performances of the proposed parametric model.

\section{References}

Alexander P., Allen S. and Dutta D., (1998), "Part orientation and build cost determination in layered manufacturing”, Computer Aided Design, vol. 30 n5, pp 343-356.

Byun Hong-Seok, Lee Kwan H., (2006), "Determination of the optimal build direction for different rapid prototyping processes using multi-criterion decision making”, Robotics and Computer Integrated Manufacturing, vol.22, pp. 69-80.

Cheng W., Fuh J., Nee A., Wong YS, Loh HT and Miyazawa T., (1995), “Multi-objective optimization of part building orientation in stereolithography”. Rapid Prototyping Journal, vol.1, n4, pp.339-45.

Frank D. and Fadel G., (1995), "Expert system-based selection of the preferred direction of build for rapid prototyping processes”, Journal of Intelligent Manufacturing, vol. 6, n5, pp.339-345.

Giannatsis J., Dedoussis V., Laios L., (2001), "A study of the build-time estimation problem for Stereolithography systems", Robotics and Computer Integrated Manufacturing, vol. 17 pp. 295-304.

Gogate A. S. and Pande S. S., (2007) "Intelligent layout planning for rapid prototyping”, International Journal of Production Research, pp. 1-25. 
Huang H., Wang L. and Gu Z., (2003), "A Web-based custom service system for rapid prototyping”, Proceedings of the 2003 IEEE International Conference on Systems, Man and Cybernetics.

Jiangand P. Fukuda S., (2001), “TeleRP — an Internetweb-based solution for remote rapid prototyping service and maintenance", International Journal of Computer Integrated Manufacturing, vol. $14, \mathrm{n}^{\circ} 1$, pp. $83-94$.

Kechagias J., Maropoulos S. and Karagiannis S., (2004), "Process build time estimator algorithm for lamined object manufacturing”, Rapid Prototyping Journal, vol. 10, n. 5, pp. 297-304.

Luo R.C., Tzou J. H. and Lan C. C., (2003), “The development of Web-based E-business System for Rapid Prototyping Manufacturing”, IECON '03, the 29th Annual Conference of the IEEE, 2-6 Nov., vol. 2, pp. 1290- 1295.

Luo R. C., Lan C. C., Tzoul J. H., and Chen C. C. (2004), "The development of WEB based Ecommerce platform for Rapid Prototyping system", Proceedings of the 2004 IEEE International Conference on Networking. Sensing \& Control. Taipei, Taiwan, March, pp. 21-23.

Majhi J., Janardan R., Smid M. and Schwerdt J., (1998), "Multi-criteria geometric optimization problems in layered manufacturing”, Proceedings of the 14th Annual ACM Symposium on Computational Geometry, pp. 19-28.

Xu F., Oh T.L., Wong Y.S., (1999), "Consideration of optimal orientation for different rapid prototyping”, Rapid Prototyping Journal, vol. 5, n², pp. 54-60.

Zhao J., Liu W. and Wu J., (2006), "Determination of Optimal Build Orientation Based on Satisfactory Degree Theory for RPT", Journal of CAD/CAM, vol.6, $\mathrm{n}^{\circ} 1$. 


\section{layer i-th}

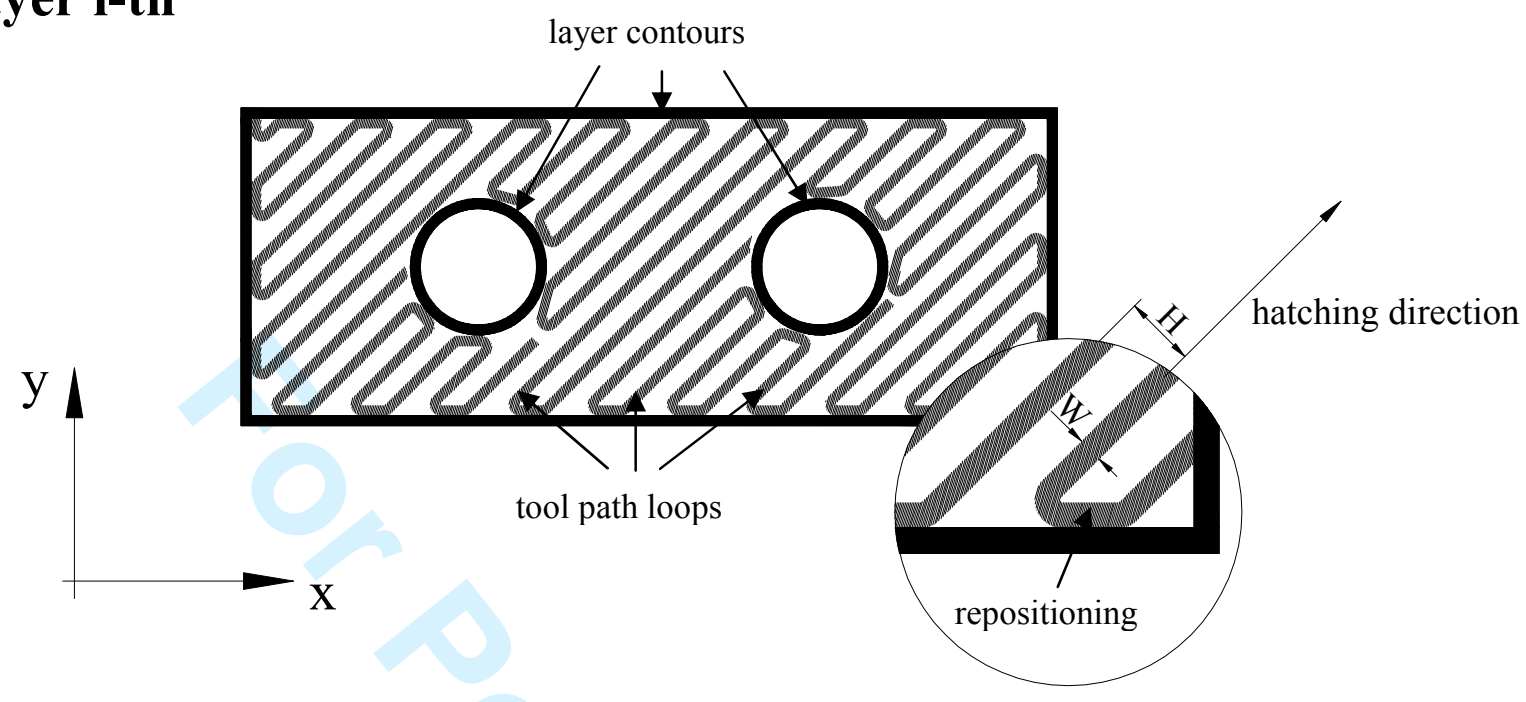

Figure 1: Layer filling path

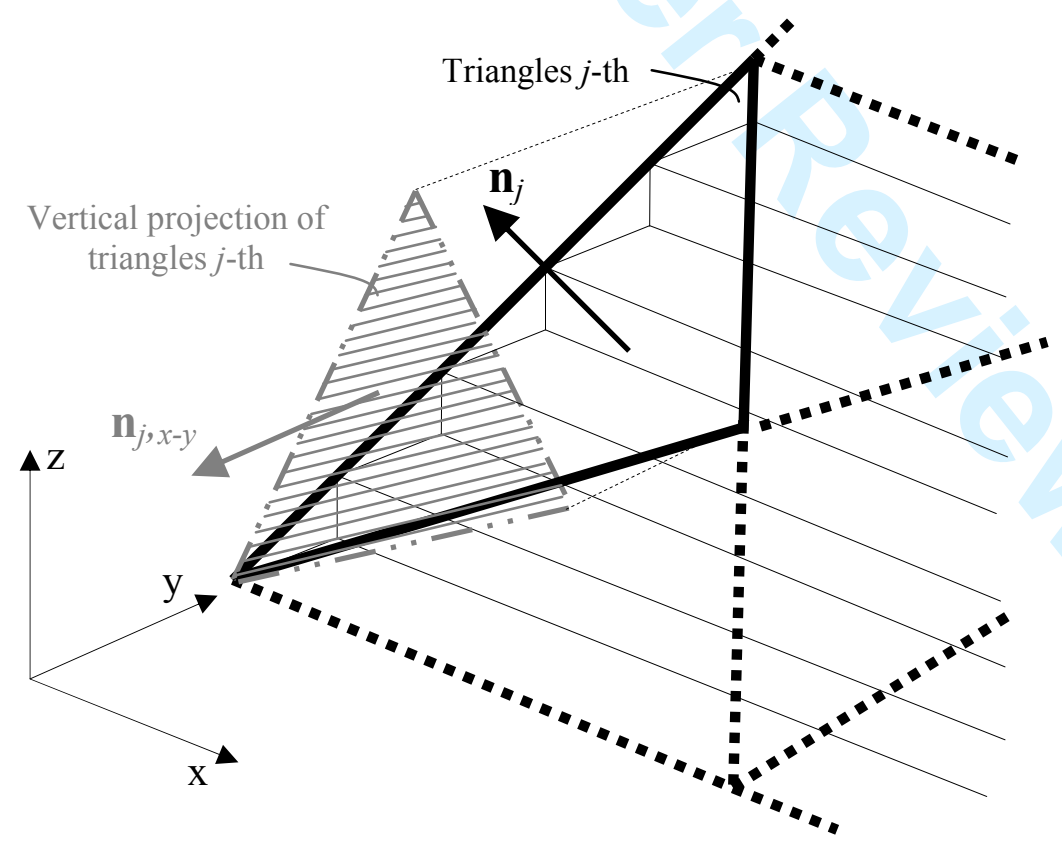

Figure 2: Vertical projection of the $j^{\text {th }}$ triangle

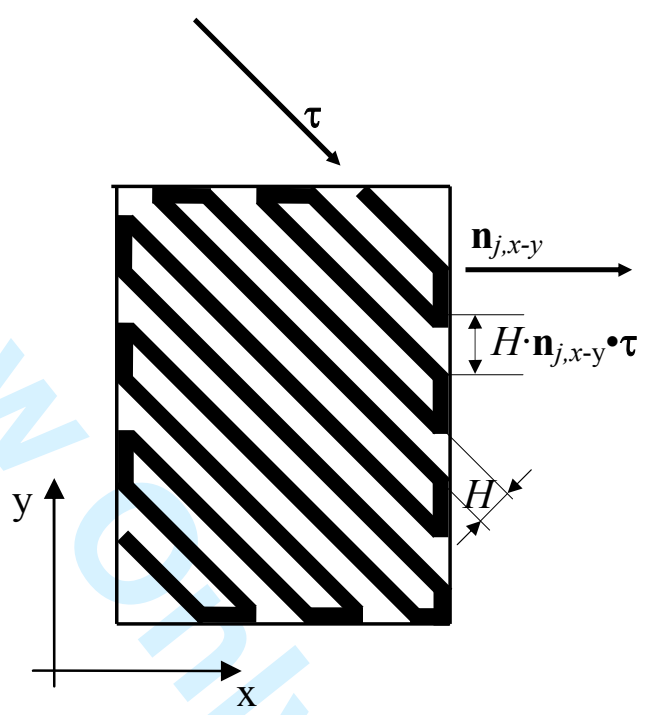

Figure 3: Hatch distance and tool repositioning number 

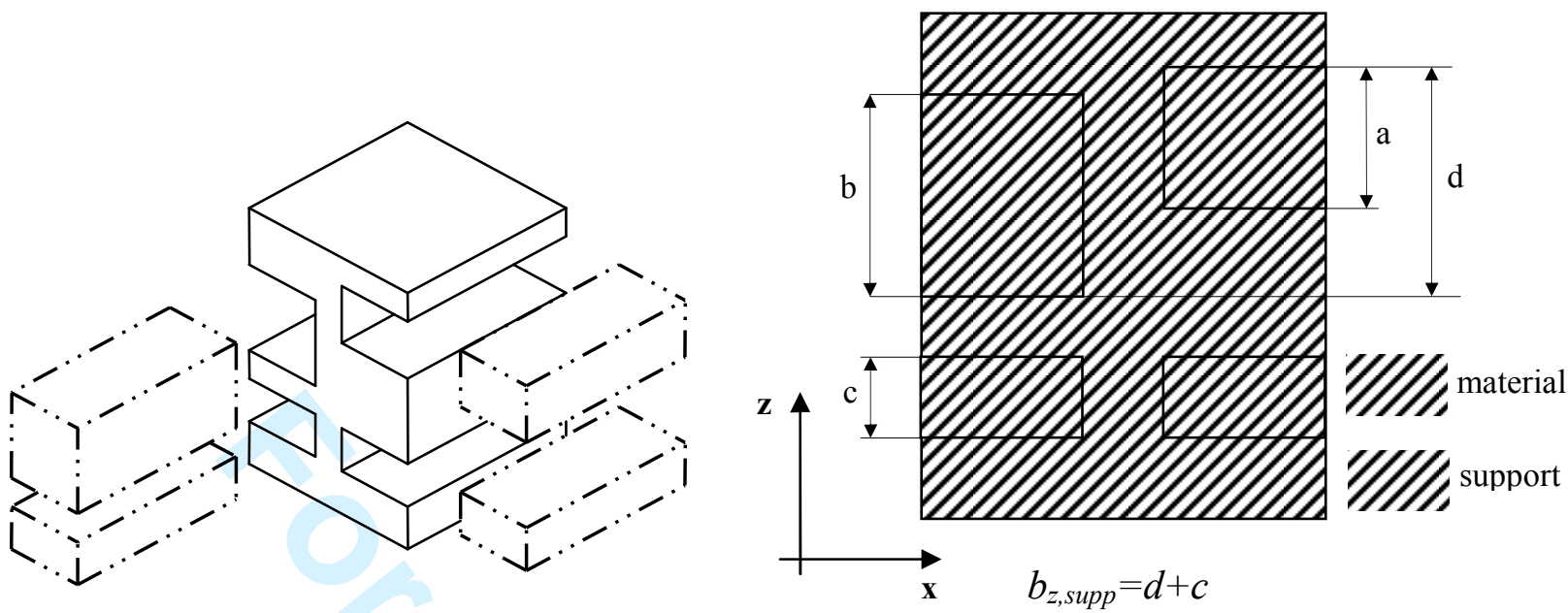

Figure 4: Rule for the evaluation of supports' total height $\left(b_{z, \text { sup }}\right)$.

\begin{tabular}{l|l} 
Company & Technimold s.r.l. \\
\hline Process & FDM \\
\hline Machine & Dimension SST \\
\hline Maximum working volume & $203 \times 203 \times 205 \mathrm{~mm}$ \\
\hline Deposition direction & $45^{\circ}$ \\
\hline L material and support & $0.254 \mathrm{~mm}$ \\
\hline H material and support & $0.5 \mathrm{~mm}$ \\
\hline W material and support & $0.5 \mathrm{~mm}$ \\
\hline
\end{tabular}

Table 1: Principal technical specifications of the used layer manufacturing machine.

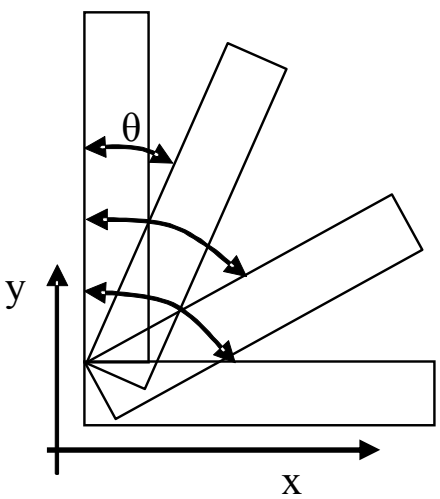

a)

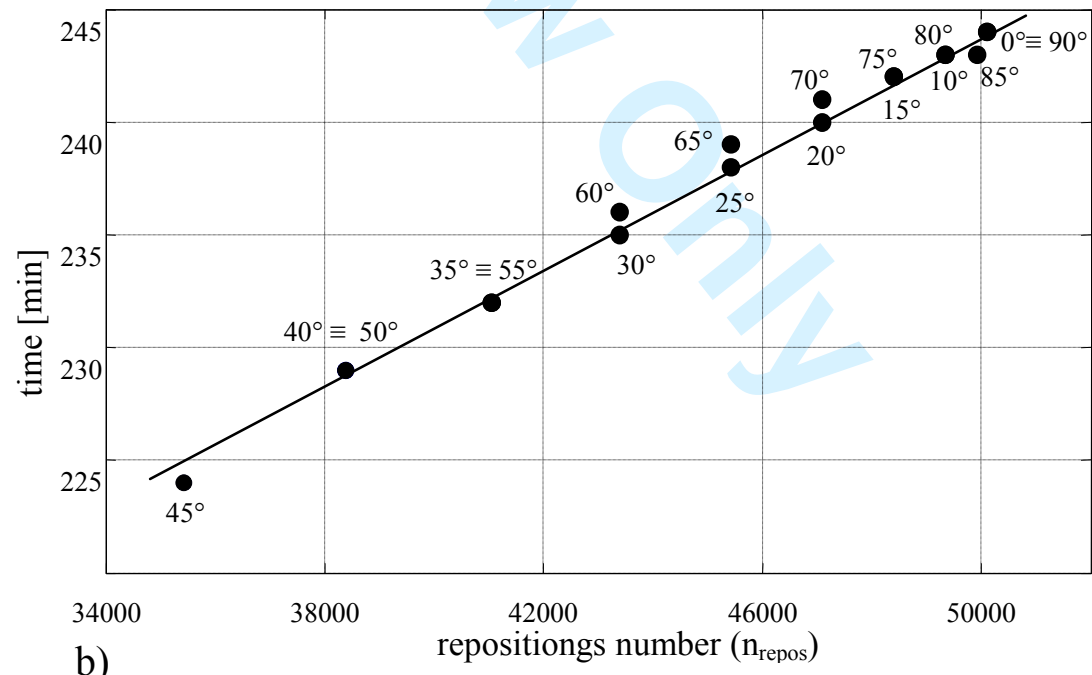

b)

Figure 5: Build time as a function of estimated repositioning number 


\begin{tabular}{|c|c|}
\hline Reflerence & Ratios of sides \\
\hline 1 & 16 \\
\hline 2 & 9.76 \\
\hline 3 & 6.25 \\
\hline 4 & 4 \\
\hline 5 & 2.44 \\
\hline 6 & 1 \\
\hline
\end{tabular}

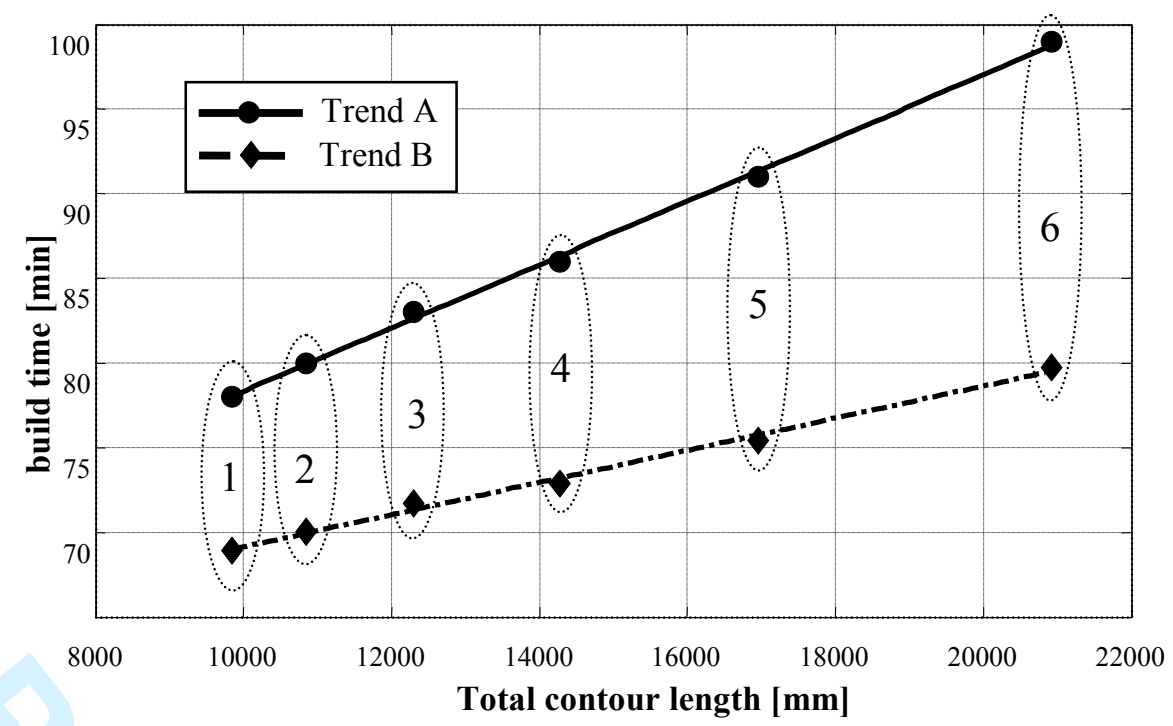

Figure 6: Influence of the total contour length on build time of prismatic prototypes

\begin{tabular}{|c|c|c|c|c|c|c|c|c|}
\hline Coefficient & $t_{s, \text { mat }}$ & $t_{w, \text { mat }}$ & $\alpha_{\text {mat }}$ & $\beta_{\text {mat }}$ & $t_{s, \text { sup }}$ & $t_{w, \text { sup }}$ & $\alpha_{\text {sup }}$ & $\beta_{\text {sup }}$ \\
\hline Value & 0,000249 & 0,3116 & 0,001318 & 0,0009 & 0,000455 & 0,2441 & 0,0009 & 0,0004 \\
\hline
\end{tabular}

Table 2: Values of the eight coefficients of the mathematical model for build time estimation.

\begin{tabular}{|c|c|c|c|c|}
\hline \multirow[b]{2}{*}{ Name } & \multicolumn{2}{|c|}{ Build time [min] } & \multicolumn{2}{|c|}{$\begin{array}{ll}\text { Error }[\%] \\
\end{array}$} \\
\hline & $\begin{array}{c}\text { Dimension } \\
\text { SST }\end{array}$ & $\begin{array}{c}\text { Proposed } \\
\text { model }\end{array}$ & $\begin{array}{c}\text { Proposed } \\
\text { model }\end{array}$ & In literature \\
\hline Test case $n^{\circ} 1$ & 222 & 192,8 & $-15,13$ & 11,4 (Huang et al., 2003) (** $^{* *}$ \\
\hline Test case $n^{\circ} 2$ & 315 & 308,07 & $-2,25$ & 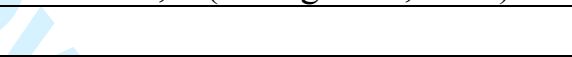 \\
\hline Test case $n^{\circ} 3$ & 334 & 293,3 & $-13,88$ & 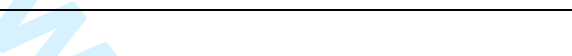 \\
\hline Test case $n^{\circ} 4$ & 548 & 557,4 & 1,69 & 9.41 (Kechagias et al., 2004) $^{* * *}$ \\
\hline Test case $n^{\circ} 5$ & 98 & 108,25 & 9,47 & 13.33 (Kechagias et al., 2004) $^{* *}$ \\
\hline Test case $n^{\circ} 6$ & 410 & 413,96 & 0,96 & 2.56 (Kechagias et al., 2004) $^{* *}$ \\
\hline $\begin{array}{ll}* & \text { FDM manuf } \\
* * & \text { Manufacturi } \\
* * * & \text { Laminated }\end{array}$ & $\begin{array}{l}\text { rocess. } \\
\text { not speci } \\
\text { ufacturing }\end{array}$ & & & \\
\hline
\end{tabular}

Table 3: Results obtained for the six test cases selected 


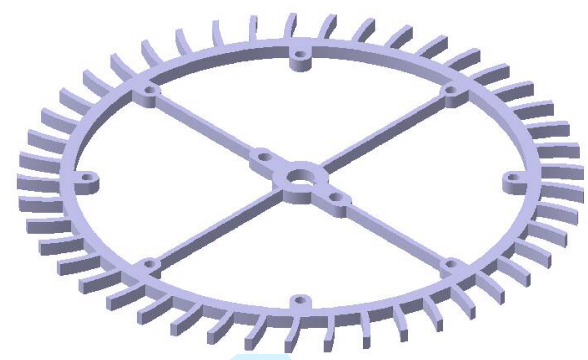

a) test case $\mathbf{n}^{\circ} \mathbf{1}$ (Huang et al., 2003)

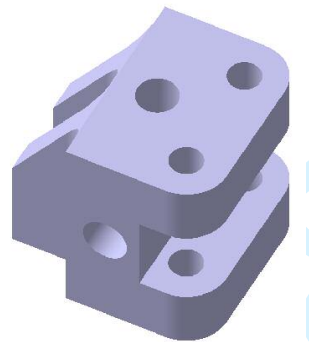

f) test case $\mathbf{n}^{\circ} \mathbf{3}$ (Byun and Lee, 2006)

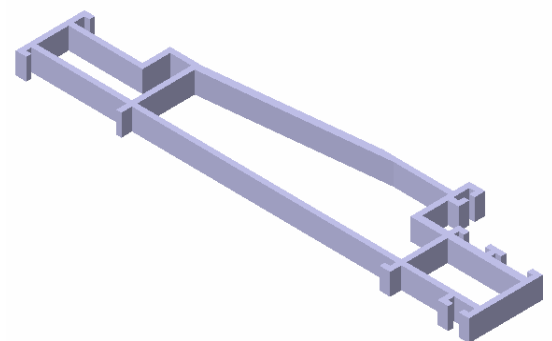

c) test case $n^{\circ} 5$ (Kechagias et al., 2004)

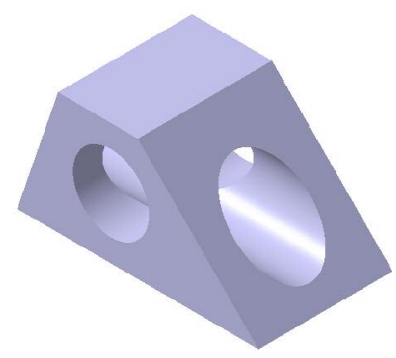

e) test case $\mathbf{n}^{\circ} \mathbf{2}$ (Byun and Lee, 2006)

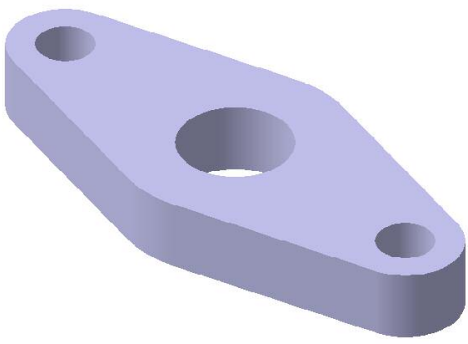

b) test case $n^{\circ} \mathbf{4}$ (Kechagias et al., 2004)

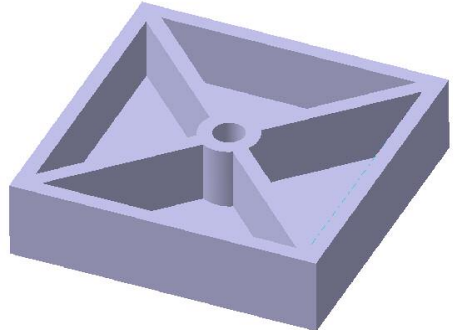

d) test case $\mathbf{n}^{\circ} \mathbf{6}$ (Kechagias et al., 2004)

Figure 7: Test cases used to validate the proposed method 